\title{
Outcome of liver disease in children with Alagille syndrome: a study of 163 patients
}

\author{
P Lykavieris, M Hadchouel, C Chardot, O Bernard
}

\begin{abstract}
Background and aims-Various opinions have been expressed as to the long term prognosis of liver disease associated with Alagille syndrome (AGS).

Patients and methods-We reviewed the outcome of 163 children with AGS and liver involvement, investigated from 1960 to 2000 , the end point of the study (median age 10 years (range 2 months to 44 years)) being death, liver transplantation, or the last visit.

Results-At the study end point, of the 132 patients who presented with neonatal cholestatic jaundice, 102 remained jaundiced, 112 had poorly controlled pruritus, and 40 had xanthomas; cirrhosis was found in 35/76 livers, varices in 25/71 patients, and liver transplantation had been carried out in 44 patients (33\%). Forty eight patients died, 17 related to complications of liver disease. Of 31 patients who did not present with neonatal cholestatic jaundice, five were jaundiced at the study end point, 17 had well controlled pruritus, and none had xanthomas; cirrhosis was found in $6 / 18$ patients, varices in $4 / 11$, and none underwent liver transplantation. Nine patients died, two of liver disease. In the whole series, actuarial survival rates with native liver were $51 \%$ and $38 \%$ at 10 and 20 years, respectively, and overall survival rates were $68 \%$ and $62 \%$, respectively. Neonatal cholestatic jaundice was associated with poorer survival with native liver $(p=0.0004)$.

Conclusions-The prognosis of liver disease in AGS is worse in children who present with neonatal cholestatic jaundice. However, severe liver complications are possible even after late onset of liver disease, demanding follow up throughout life.

(Gut 2001;49:431-435)
\end{abstract}

Keywords: Alagille syndrome; cholestasis; end stage liver disease; liver transplantation

Syndromic paucity of interlobular bile ducts (Alagille syndrome, AGS) is an autosomal dominant disorder defined clinically by the association of at least three of five major features (chronic cholestasis, congenital heart disease, "butterfly-like" vertebrae, posterior embryotoxon, and peculiar facies) and genetically by mutations in the fagged 1 gene. $^{1-3}$ Expression of AGS varies from a mild phenotype to severe diseases of the heart or kidney and to the consequences of chronic cholestasis, including liver failure. AGS has long been said to have a relatively good long term prognosis in terms of liver disease ${ }^{4}{ }^{5}$; however, it is now well recognised that some patients with AGS can present with severe complications of liver disease ${ }^{6-12}$ We therefore reviewed the charts of 174 patients with AGS presenting in childhood to evaluate the role of the liver condition in mortality, morbidity, and long term outcome.

\section{Patients and methods}

One hundred and seventy four children with AGS (106 boys) were investigated at Bicêtre Hospital between 1960 and 2000. Twenty four had a sibling affected by AGS; seven of these siblings are included in this series as well as two offspring of affected mothers. All patients had at least three of the five major clinical features. Thirteen children with severe neonatal jaundice underwent Kasai operation for suspected biliary atresia before the diagnosis of AGS was established. Cholecystostomies with external bile drainage and cholecystojejunal anastomoses were performed in 24 and six patients, respectively. End stage liver disease was defined by the combination of the following laboratory tests: serum bilirubin concentration $>300 \mu \mathrm{mol} / 1$, serum albumin concentration $<35 \mathrm{~g} / \mathrm{l}$, and prolonged prothrombin time in spite of treatment with parenteral vitamin $\mathrm{K}$. Investigations of portal hypertension included upper digestive endoscopy, ultrasonography, and angiography. Therapy included various antipruritus drugs over time and supplementation as necessary with parenteral or oral fat soluble vitamins. Hypercaloric continuous nocturnal enteral feeding was performed in 39 children with severe growth and height retardation.

\section{STATISTICAL ANALYSIS}

Categorial data were compared using the $\chi^{2}$ test with Yates' correction if indicated. Continuous data were compared using the $t$ test. Survival rates were calculated according to the Kaplan-Meier method, the results being expressed as value (SEM) and compared using the log rank (Mantel-Cox) test. Multivariate analysis was performed using Cox's proportional hazard model, and relative risks (RR) were calculated with $95 \%$ confidence intervals (CI). All significance tests were two tailed and differences were considered to be statistically significant at $p<0.05$. All analyses were performed with the Statview 4.51.1 software (Abacus concepts Inc., Berkeley, California, USA).

Abbreviations used in this paper: AGS, Alagille syndrome; LT, liver transplantation; RR, relative risk.
France

Accepted for publication 12 February 2001 
Table 1 Clinical signs and outcome at the study end point in 163 patients with Alagille syndrome and chronic liver disease. The study end point was defined as either death, liver transplantation, or last follow up

\begin{tabular}{|c|c|c|c|}
\hline $\begin{array}{l}\text { No patients } \\
\text { Median age (range) }\end{array}$ & $\begin{array}{l}\text { Patients with neonatal } \\
\text { cholestatic jaundice } \\
132 \\
9 y(2 \operatorname{mos}-29 y)\end{array}$ & $\begin{array}{l}\text { Patients with no } \\
\text { clinically patent } \\
\text { neonatal jaundice } \\
31 \\
14 \text { y (3-44) }\end{array}$ & $p$ Value \\
\hline Median age (range) & $\begin{array}{l}\text { No positive/No patients } \\
\text { studied }\end{array}$ & $\begin{array}{l}\text { No positive/No patients } \\
\text { studied }\end{array}$ & \\
\hline Jaundice & $102 / 132$ & $5 / 31$ & $<0.0001$ \\
\hline Pruritus & $112 / 132^{\star}$ & $17 / 28 \ddagger$ & 0.0003 \\
\hline Xanthomas & $40 / 132$ & $0 / 31$ & 0.0004 \\
\hline Hepatomegaly & $115 / 132$ & $11 / 31$ & $<0.0001$ \\
\hline Splenomegaly & $62 / 132$ & $6 / 29$ & 0.0095 \\
\hline Cirrhosis & $35 / 76+$ & $6 / 18$ & NS \\
\hline Oesophageal varices & $25 / 715$ & $4 / 118$ & NS \\
\hline GI bleeding & $5 / 132$ & $1 / 29$ & NS \\
\hline Cholelithiasis & $6 / 132$ & $1 / 29$ & NS \\
\hline Hepacellular carcinoma & $0 / 132$ & $1 / 31$ & NS \\
\hline Liver transplantation & $44 / 132$ & $0 / 31$ & 0.0002 \\
\hline Death related to liver disease & $17 / 132$ & $2 / 31$ & NS \\
\hline \multirow[t]{2}{*}{ Dead } & $48 / 132$ & $9 / 31$ & NS \\
\hline & $\begin{array}{l}\text { Median (range)/No } \\
\text { patients studied }\end{array}$ & $\begin{array}{l}\text { Median (range)/No } \\
\text { patients studied }\end{array}$ & \\
\hline ASAT (IU/l) & $162(23-650) / 106$ & $12(25-186) / 23$ & 0.0004 \\
\hline$\gamma \mathrm{GT}(\mathrm{IU} /)$ & $408(13-2288) / 92$ & $332(28-787) / 18$ & NS \\
\hline Serum cholesterol $(\mathrm{mmol} / \mathrm{l})$ & $9.9(1.3-50.5) / 126$ & $7.4(4.8-8) / 26$ & NS \\
\hline
\end{tabular}

*Variably controlled under medical treatment.

$\$$ Well controlled under medical treatment.

†32 patients who underwent liver biopsy after one year of age and 44 patients whose liver was removed at LT.

\18 patients who underwent liver biopsy after one year of age.

$§$ Number of patients who underwent endoscopy during follow up.

\section{Results}

Of the 174 patients studied, 81 displayed all five major clinical features of the syndrome, 68 displayed four major features, and 25 three major features. In 132 children, 38 being small for gestational age (with a weight below the 10th percentile for gestational age), the presenting symptom was neonatal cholestatic jaundice. In 42 children, two being small for gestational age (significantly less than in the other group, $\mathrm{p}<0.01$ ), there was no history of clinically evident neonatal jaundice and presenting symptoms occurred at a median age of 33 months (range 4 months to 10 years) consisting of hepatomegaly $(n=12)$, cardiac murmur $(n=9)$, failure to thrive $(n=8)$, pruritus $(n=4)$, jaundice $(n=3)$, and fortuitous finding of abnormal liver function tests $(n=6)$. Eleven of these 42 patients did not present with any clinical or biochemical signs of cholestasis and are not included in the study. Therefore, 163 children with AGS and chronic cholestasis form the basis of this report. Median age at study end point was 10 years (range 2 months to 44 years).

\section{CHILDREN WITH NEONATAL JAUNDICE (TABLE} 1).

At study end point, 102 children remained jaundiced (median age nine years), median total serum bilirubin value being $198 \mu \mathrm{mol} / 1$ (range 37-1030). In the remaining 30 patients, jaundice disappeared at ages ranging from six months to 18 years (median 2 years 10 months). Pruritus was noted for the first time at a median age of seven months in all surviving children (range 1-28 months). In 20 children pruritus disappeared completely and permanently at a median age of 12 years 6 months (range 4-23 years). In all other patients pruritus persisted throughout life with varying degrees depending on the type of drug used and on compliance with therapy. Xanthomas were noted at a median age of one year nine months (range 9 months to 10 years) in 69 patients. They persisted until liver transplantation (LT), death, or last follow up in 40 patients. In the remaining 29 children, xanthomas disappeared at a median age of seven years (range 3-18 years). Hepatomegaly remained present in 38 patients who died and in all patients in whom LT was performed. In patients surviving without LT, hepatomegaly decreased progressively with age and was no longer detectable in 17 of 21 patients after age 15 years. Splenomegaly was found during follow up in 84 patients; it progressively regressed in 21 patients and one patient underwent splenectomy. Results of biochemical, histological, and endoscopic tests carried out at the study end point are indicated in table 1 . Six patients presented with cholelithiasis at a median age of four years (range 3-8 years). Gastrointestinal bleeding from oesophageal varices occurred in five patients (including one with associated portal vein obstruction) at a median age of three years nine months (range 13 months to 23 years) and was the cause of death in three patients. Twenty three patients had one or more bone fractures and three patients developed large joint arthropathy after age nine years. A partial improvement in jaundice, pruritus, and liver tests was observed in four of 30 patients who underwent cholecystostomy and/or cholecystojejunostomy after follow up periods ranging from three weeks to four months; no significant improvement was observed in the remaining 26 children.

Forty four patients underwent liver transplantation in various centres at a median age of six years nine months (range 2 years 9 months to 28 years), including 31 children in our group. Nine of the 44 transplanted patients had previously undergone a Kasai procedure. At the time of transplantation all patients were jaundiced and weight (mean-2.6 SD) and height (mean-2.2 SD) retardation were present in 38 patients. Indications for liver transplantation were refractory pruritus in 36 , disfiguring xanthomas in 32 , bone fractures in 15, and/or patent signs of end stage liver disease in five, all resulting in a very poor quality of life. Ten year survival after LT was 77 (6) $\%$. Growth in terms of height was studied in 23 transplanted patients less than 16 years of age at the time of LT and with more than two years of follow up after LT: a mean gain of 1.25 SD was observed during a mean period of 5.5 years. Four children died of end stage liver disease before the era of LT at ages ranging from one to 17 years and two are currently awaiting LT.

31 CHILDREN WITH CHRONIC LIVER DISEASE BUT WITHOUT NEONATAL CHOLESTATIC JAUNDICE (TABLE 1).

Fifteen children remained jaundice free until the last follow up at a median age of 14 years (range 3-44 years); in 16 patients jaundice 
Table 2 Causes of death in 57 patients with Alagille syndrome and chronic liver disease

\begin{tabular}{|c|c|c|c|c|c|c|}
\hline & \multicolumn{3}{|c|}{ Patients with neonatal cholestatic jaundice } & \multicolumn{3}{|c|}{$\begin{array}{l}\text { Patients with no clinically patent neonatal } \\
\text { jaundice }\end{array}$} \\
\hline & \multirow[b]{2}{*}{$n$} & \multicolumn{2}{|l|}{ Age } & \multirow[b]{2}{*}{$n$} & \multicolumn{2}{|l|}{ Age } \\
\hline & & Median & Range & & Median & Range \\
\hline Liver failure & 4 & $3 y$ & $1-17 \mathrm{y}$ & 2 & 11 y $9 / 12$ & $10-13$ y $6 / 12$ \\
\hline Portal hypertension & 3 & $8 \mathrm{y}$ & $13 \operatorname{mos}-23$ y & 0 & & \\
\hline Liver transplantation & 10 & 5 y $8 / 12$ & 4 у $7 / 12-12$ y & 0 & & \\
\hline Haemorrhage & 6 & 3 y $6 / 12$ & $3-5 y$ & 1 & & $23 y$ \\
\hline Cardiac abnormalities & 5 & 2 y $9 / 12$ & $3 \operatorname{mos}-7 y$ & 1 & & 4 mos \\
\hline Infection & 5 & $1 \mathrm{y}$ & $2 \operatorname{mos}-26$ y & 3 & $10 \mathrm{y}$ & 6 mos -25 y $6 / 12$ \\
\hline Post surgery & 3 & 2 y $6 / 12$ & 1 y $6 / 12-5$ y & 0 & & \\
\hline Renal failure & 3 & $2 \mathrm{y}$ & 9 mos -8 y & 0 & & \\
\hline Lung aspiration syndrome & 2 & $4 \mathrm{mos}$ & $3 \mathrm{mos}-5 \mathrm{mos}$ & 0 & & \\
\hline Sudden death & 1 & & $1 \mathrm{y}$ & 0 & & \\
\hline Heart-lung transplantation & 0 & & & 1 & & $4 \mathrm{y}$ \\
\hline During general anaesthesia & 1 & & $6 \mathrm{y}$ & 0 & & \\
\hline Accidental death & 0 & & & 1 & & $17 \mathrm{mos}$ \\
\hline Unknown & 5 & $4 y$ & 2 y $6 / 12-11$ y & 0 & & \\
\hline Total & 48 & & & 9 & & \\
\hline
\end{tabular}

appeared at a median age of four years (range 4 months to 20 years). Jaundice was permanent until death (median age 12 years) in five of these 16 patients and intermittent in the remaining 11. Pruritus was present in 24 patients and noted for the first time at a median age of 14 months (range 4 months to 6 years); it disappeared spontaneously in seven patients at ages ranging from six to 20 years (median 13 years). In the remaining 17 patients, pruritus was controlled by medical treatment. Xanthomas were found in one patient at age two years and disappeared one year later. Liver enlargement was present in 20 patients. Hepatomegaly persisted in nine of the 10 patients who died and regressed progressively in eight of 10 who survived after age 15. Splenomegaly was present in six patients. Results of biochemical, histological, and endoscopic tests, carried out at the study end point, are indicated in table 1 . Of the four patients with oesophageal varices, one presented with gastrointestinal bleeding. Two patients died from end stage liver disease at age 10 and 13.5 years, respectively, before the era of LT. Cholelithiasis was found in one patient at age three years. Another patient presented with hepatocellular carcinoma at age 44 years.

OVERALL OUTCOME

Overall survival of the 163 patients was 68 (4) $\%$ at 10 years and $62(4) \%$ at 20 years. Overall survival of AGS patients was not significantly different in the two subgroups of patients with and without neonatal cholestatic jaundice (10 year survival rates 65 (4) $v 79$ (8)\%, respectively; NS). Overall survival of AGS patients was not significantly different in patients born before or after 1986 when LT became widely available (10 year survival rates 67 (3)\% v 70 (3) \%, respectively; NS). In 60 patients born after 1986, overall survival was not significantly different in the subgroups of patients who did or did not undergo LT (10 year survival rates $70(10) \%$ v 71 (9)\%, respectively; NS). Fifty seven patients died at a median age of four years (range 2 months to 26 years). Causes of death are listed in table 2; $33 \%$ of deaths were related to liver disease

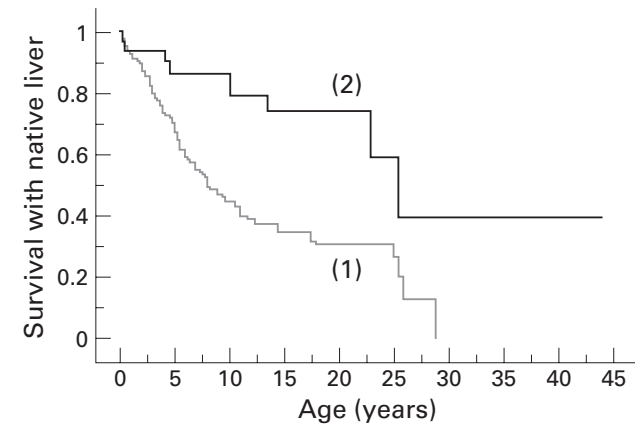

Figure 1 Survival with native liver in 163 patients with Alagille syndrome and chronic liver disease. 1, 132 patients with neonatal cholestatic jaundice; 2, 31 patients with late onset cholestasis $(p=0.0004)$.

either directly or after LT. Survival with native liver was $51(4) \%$ at 10 years and $38.5(4.5) \%$ at 20 years. In the univariate analysis, 10 year survival with native liver was worse in patients with neonatal cholestatic jaundice than in those with late onset of cholestasis (45 (5)\% $v 79$ $(8) \% ; p=0.0004$ ) (fig 1), in patients with xanthomas than in those without xanthomas $(43(6) \% v 60(6) \% ; p=0.017)$, and in patients who underwent a Kasai operation than in those who did not (38 (13)\% v $54(4) \%$; $\mathrm{p}=0.048)$. In the multivariate analysis, neonatal cholestatic jaundice was the only independent prognostic factor (RR 2.52; 95\% CI 1.25-5.88; $\mathrm{p}=0.012$ ) whereas xanthomas and Kasai operation were not (no xanthomas: RR $0.78,95 \%$ CI 0.49-1.23, NS; no Kasai operation: RR 0.65, 95\% CI $0.35-1.21, \mathrm{NS})$. Thirty nine patients were alive at age 18 or more at the latest follow up: 21 are currently employed as secretaries, factory workers, farmers, stretcher bearers or nurses, and one is a professional violinist. Three others are university students. Four women gave birth to six children, three of whom also have AGS.

\section{Discussion}

Because of the multisystemic nature of the syndrome and of the sometimes severe cardiac and renal involvement, the relatively slow progression of the liver condition towards liver failure in many children compared with other 
cholestatic diseases presenting in early childhood such as biliary atresia or progressive familial intrahepatic cholestasis, and also the relatively short follow up, the clinical significance of liver disease in children with AGS may have been underestimated in the first reports of this entity; it was considered a "benign syndrome of intrahepatic cholestasis", ${ }^{4}$ liver complications were considered responsible for death in $5 \%$ of patients, ${ }^{5}$ and indications for LT were considered to be "rare". ${ }^{5}$ Over the past 10 years however there have been reports from small numbers of cases and from larger series of patients suggesting that the severity of liver involvement may be higher than originally thought. Liver failure and/or hepatocellular carcinoma may occur in children as young as $2-4$ years $^{13-15}$ as well as in a few adults after apparently many years of moderate cholestasis $^{8}$; LT has been used in an increasing number of children either because of liver failure or to improve the quality of life in children with severe chronic cholestasis. ${ }^{79}$ Two recent reports indicated $37 \%$ and $50 \% 20$ year survival rates with native liver. ${ }^{10}{ }^{11}$ However, in the largest series of patients with AGS reported so far, 20 year overall actuarial survival was predicted to be $75 \% .{ }^{12}$ As suggested, ${ }^{10}$ differences in estimation of the long term prognosis may be due to the variable mode of inclusion of patients in the studies, some including more severely sick children originating from liver transplant centres. ${ }^{11}$

The results of the study reported here concern a large number of children with AGS investigated in the same unit over 40 years. They indicate that the liver condition in patients with AGS presenting in childhood is indeed severe in many instances and that the impact of the liver condition is greater in children who present with neonatal cholestatic jaundice than in children whose symptoms occur later in life. In fact, according to these results, the consequences of liver disease in children presenting with neonatal cholestatic jaundice are more severe in the short and medium term: $77 \%$ of children remain jaundiced versus $16 \%$ of children presenting later in life. Pruritus is more frequent and more difficult to treat. Xanthomas are present in 30\% of children while they are absent in children from the late onset group. Liver and spleen enlargement are also twice as frequent in children with neonatal onset and LT was performed only in children of this group. Ten year survival with native liver was $45 \%$ in the neonatal onset group versus $79 \%$ in the group of children with late onset, and the expected mortality directly related to the liver condition was higher in the neonatal onset group if one adds up patients who died before the era of LT and patients who presented with end stage liver disease at the time of LT and who would have died without LT. There are however several points that must be stressed to moderate these assertions. Firstly, it remains true that within the group of children with neonatal onset there is a subgroup of patients, albeit a minority, in whom a definite improvement in the clinical and biochemical signs of cholestasis occurs with time. Secondly, overall survival of AGS patients is comparable in the two groups, averaging $70 \%$. Extrahepatic causes of deaths are frequent in both groups. Thirdly, it is worth noting that at least within the limits of this retrospective study, there was not much difference between the neonatal and late onset groups in the incidence of histologically proved cirrhosis and portal hypertension, as shown by oesophageal varices on endoscopy, and of gastrointestinal bleeding. In particular, the only patient with hepatocellular carcinoma was a 44 year old adult in the late onset group. Hepatocellular carcinoma has even been reported in a patient with AGS and no cirrho$\operatorname{sis}^{16}$ and there have been patients with a clinically moderate disease in whom repeated liver biopsies displayed signs of cirrhosis only well into adulthood. ${ }^{8}$

The timing of LT should be considered carefully. On the one hand, successful LT markedly improves the quality of life and one could be tempted to perform LT early on for this reason. ${ }^{17}$ On the other hand, signs of end stage liver disease were present in a minority of patients $(11 \%)$ at the time of transplantation and the $20 \%$ death rate after LT may prove unacceptable in the others. Therefore, one has to weigh carefully the expected improvement in quality of life versus the risk of untimely death.

In conclusion, children with AGS presenting with neonatal cholestatic jaundice have to be followed in a cautious way because of the high risk of complications of the liver disease and of severe cholestasis, which may require LT at some time during follow up. Severe hepatic complications may also occur in children in whom signs of cholestasis improve with time as well as in patients presenting later in life, implying careful follow up throughout life.

We would like to thank Drs L Alteroche, C Buffet, J Couchot, A Dabadie, A Estrada, P Hadchouel, D Houssin, M Messner, P Mortellaro, F Risser, C Saint-Aimé, and J Sarles for providing information on some of the patients.

1 Alagille D, Odièvre $\mathrm{M}$, Gautier $\mathrm{M}$, et al. Hepatic ductular hypoplasia associated with characteristic facies, vertebral malformations, retarded physical, mental and sexual development, and cardiac murmur. F Pediatr 1975;86:63-71.

$2 \mathrm{Li}$ L, Krantz ID, Deng Y, et al. Alagille syndrome is caused by mutations in human Jagged 1, which encodes a ligand for Notch 1. Nat Genet 1997;6:243-51.

3 Oda T, Elkahloun AG, Pike BL, et al. Mutations in the human Jagged 1 gene are responsible for Alagille syndrome. Nat Genet 1997;16:235-42.

4 Riely C, Cotlier E, Jensen P, et al. Arteriohepatic dysplasia: a benign syndrome of intrahepatic cholestasis with multiple organ involvement. Ann Intern Med 1979;91:520-7.

5 Alagille D, Estrada A, Hadchouel M, et al. Syndromic paucity of interlobular bile ducts (Alagille syndrome or arteriohepatic dysplasia): review of 80 cases. $\mathcal{F}$ Pediatr 1987;110: hepatic dysp

6 Krantz ID, Piccoli DA, Spinner NB. Alagille syndrome. $f$ Krantz ID, Piccoli DA, Sp
Med Genet 1997;34:152-7.

7 Tzakis AG, Reyes J, Tepetes K, et al. Liver transplantation for Alagille's syndrome. Arch Surg 1993;128:337-9.

8 Schwarzenberg SJ, Grothe RM, Sharp HL, et al. Long-term complications of arteriohepatic dysplasia. Am $\mathcal{F}$ Med 1992; 93:171-6.

9 Cardona J, Houssin D, Gauthier F, et al. Liver transplantation in children with Alagille syndrome. A study of twelve cases. Transplantation 1995;60:339-42.

10 Hoffenberg EJ, Narkewicz MR, Sondheimer JM, et al. Outcome of syndromic paucity of interlobular bile ducts (Alagille syndrome) with onset of cholestasis in infancy. $\mathcal{F}$ Pediatr 1995;127:220-4.

11 Quiros-Tejeira RE, Ament ME, Heyman MB, et al. Variable morbidity in Alagille syndrome: a review of 43 cases. $\mathcal{F}$ Pediatr Gastroenterol Nutr 1999;29:431-7. 
12 Emerick KM, Rand EB, Goldmuntz E, et al. Features of Alagille syndrome in 92 patients: frequency and relation to prognosis. Hepatology 1999;29:822-9.

13 Kaufman SS, Wood P, Shaw BW, et al. Hepatocarcinoma in a child with Alagille syndrome. Am $\mathcal{F}$ Dis Child 1987;141: 698-700.

14 Békassy AN, Garwicz S, Wiebe T, et al. Hepatocellular carcinoma associated with arteriohepatic dysplasia in a 4-year-old girl. Med Pediatr Oncol 1992;20:78-83.
15 Deprettere A, Portmann B, Mowat AP. Syndromic paucity of intrahepatic bile ducts: diagnostic difficulty; severe morbidity throughout early childhood. I Pediatr Gastroenterol Nutr 1987;6:865-71.

6 Adams PC. Hepatocellular carcinoma associated with arteriohepatic dysplasia. Dig Dis Sci 1986;31:438-42.

17 Mc Millan JC, Sheperd R, Heritage M. Arteriohepatic dysplasia (Alagille syndrome; Watson-Alagille syndrome). Baillieres Clin Gastroenterol 1998;12:275-91. 